\title{
The Correlation Between Delayed Surgical Therapy After the Diagnosis of Pilonidal Sinus Disease and Relapse, Labor Loss, and Costs
}

Turgay Karatas ${ }^{1}$, Murat Kanlioz ${ }^{2}$

1. Anatomy, Inönü University, Malatya, TUR 2. General Surgery, Beylikdüzü Kolan Hospital, Istanbul, TUR

Corresponding author: Murat Kanlioz, muratkanlioz@gmail.com

\section{Abstract}

\section{Introduction}

There has been no detailed study of the relationship between recurrence and symptom duration in pilonidal sinus disease. The aim of this study was to explore the correlation between delayed surgical therapy after symptoms appear in sacrococcygeal pilonidal sinus disease (SPSD) and relapse, labor loss and costs.

\section{Methods}

Patients diagnosed with SPSD were split into two groups according to symptom duration before surgery: 30 days or less (G1) and more than 30 days (G2). Patients included those who underwent Limberg flap reconstruction (LFR) for primary SPSD. The length of hospitalization during surgery, postoperative followup period, and, if any, relapse periods were obtained from patients' files. Of the patients with incomplete information, only those whose information was confirmed by phone were also covered by the study.

\section{Results}

G1 included 153 patients, including 37 (24.18\%) females and 116 (75.82\%) males. The median age in G1 was 22 years and the mean age was $23.08 \pm 8.72$ years. G2 included 214 patients, including 51 (23.83\%) females and 163 (76.17\%) males. The median age in G2 was 22 years and the mean age was $22.64 \pm 9.06$ years. The mean lengths of hospitalization in G1 and G2 were $2.14 \pm 0.86$ and $2.98 \pm 1.04$ days, respectively, and the difference between them was significant $(\mathrm{p}<0.03)$. The follow-up periods in G1 and G2 were 61.52 \pm 29.84 (12$108)$ and 64.0 $\pm 31.24(12-113)$ months, respectively. Relapse occurred in nine patients (5.8\%) in G1 and 19 patients (8.8\%) in G2, and the difference between them was significant $(\mathrm{p}<0.02)$. The mean relapse period was $3.44 \pm 6.01$ and $11.23 \pm 7.62$ months in G1 and G2, respectively, and the difference between them was significant $(\mathrm{p}<0.04)$.

\section{Conclusion}

Received 11/17/2019

Review began $11 / 21 / 2019$

Review ended 11/26/2019

Published 11/28/2019

๑) Copyright 2019

Karatas et al. This is an open access

article distributed under the terms of the Creative Commons Attribution License CC-BY 3.0., which permits unrestricted use, distribution, and reproduction in any medium, provided the original author and source are credited.

\section{Categories: General Surgery}

Keywords: pilonidal sinus disease, relapse, symptom duration, length of hospital stay, cost

\section{Introduction}

Therapy for pilonidal sinus disease (PSD) has remained controversial since it was first introduced by Hodges in 1880 [1]. Sacrococcygeal pilonidal sinus disease (SPSD) is an infectious disease characterized mostly by sinus orifice(s) in the midline, approximately $5 \mathrm{~cm}$ from the anus, seen in the "natal cleft" and sacrococcygeal region [2]. Though the debate on whether it is congenital or acquired has been ongoing for a long time, it is today widely accepted that the disease is acquired (3). The disease occurs at an earlier age in women, mostly between 20 and 25 years of age. The female-to-male ratio ranges from 1:3 to 1:5 [3-4]. It is common knowledge that prolonged sitting, chronic trauma to the sacrococcygeal region, oily skin, hirsutism, and obesity are among the factors increasing the occurrence of SPSD [5-6]. Beyond television, screen dependency has today been further strengthened by the outcomes of the developments in computer technologies, namely, phones, tablets, and computers [7]. In conjunction with the screen dependency, a sedentary lifestyle involving prolonged sitting results in obesity and increased SPSD rates. SPSD can be treated both medically and surgically. However, numerous papers suggest that surgery is the golden standard in its therapy, which is also supported by the results of the therapy [3-4]. In this study, we aimed to identify whether the time elapsed from symptom onset to surgery correlated with the length of hospital stay for surgery and the relapse.

\section{Materials And Methods}

The study included patients who underwent Limberg flap reconstruction (LFR) in primary SPSD from 2006 to 
2018. Those who were covered by the study included patients who were followed up postoperatively for at least a one-year period. By selecting all patients from the group, including those who underwent LFR, we intended to homogenize the groups and to more effectively evaluate the efficacy of the therapy. The patients who were admitted to our clinic once diagnosed with SPSD and underwent LFR were split into two groups according to the duration of symptoms. Those symptoms were defined as pain, swelling, and discharge in the sacrococcygeal region. Patients included in the first group (G1) had symptom duration of 30 days or less. In the second group (G2), patients had symptom duration of more than 30 days. We examined the patients based on the information available in the patients' files and follow-up forms and recorded the duration of symptoms until surgery, length of hospital stay, whether relapse occurred, and, if it occurred, the time elapsed from surgery to the occurrence of relapse. We contacted patients with incomplete information by phone and confirmed whether relapse occurred and, if it had, how much time elapsed between the surgery and the occurrence of relapse. We then compared the patients in G1 and G2 in terms of relapse rates and the length of hospital stay. The distribution between the two groups was analyzed using the KolmogorovSmirnov test. Further, the correlation between the groups was evaluated using the Chi-square test, in which p $<0.05$ was considered significant. We also used SPSS statistical software (IBM Corp., Armonk, NY) for recording and analyses.

\section{Results}

The median age in G1 was 22 years and the mean age was $23.08 \pm 8.72$ years, whereas the G2 group included 153 patients, of which 37 (24.18\%) were female and 116 (75.82\%) were male. The median age in G2 was 22 years and the mean age was $22.64 \pm 9.06$ years, and the group included 214 patients, of which 51 (23.83\%) were female and 163 (76.17\%) were male. No significant difference was found between the demographic data of the patients in both groups. In G1 and G2, the patients' mean length of hospital stay was $2.14 \pm 0.86$ days and 2.98 \pm 1.04 , respectively, which totaled $2.63 \pm 0.96$ days (G1 + G2). The difference between G1 and G2 was statistically significant in terms of the mean lengths of hospital stay $(\mathrm{p}<0.03)$. The mean follow-up period after surgery (LFR) was 61.52 \pm 29.84 months (12-108 months) in G1 and 64.01 \pm 31.24 months in G2 (12-113 months). During those follow-up periods, relapse occurred in nine (5.8\%) patients in G1, of which two were female (5.4\%) and seven were male (6\%). In G2, however, relapse occurred in 19 (8.8\%) patients, of which five $(9.8 \%)$ were female and 14 (8.5\%) were male. The relapse rates of patients in G1 were higher in males, and there was no statistical significance between them $(\mathrm{p}=0.07)$. In contrast, the relapse rates of $\mathrm{G} 2$ patients were higher in females, and the difference between them was statistically significant $(\mathrm{p}<0.05)$. When we compared G1 and G2, we found a higher rate of relapse in G2 and the difference between them was significant $(\mathrm{p}<0.02)$. The mean relapse period was found to be $13.44 \pm 6.01$ months in G1 and $11.23 \pm 7.62$ months in G2. In G2, relapse occurred earlier than in G1 and the difference between the two groups was statistically significant $(\mathrm{p}<0.04)$. Also, in both groups, about $68 \%$ of relapses occurred in the first year. Six (67\%) out of nine relapses in G1 and 13 (68\%) out of 19 relapses in G2 occurred in the first year (Table 1). 


\section{Cureus}

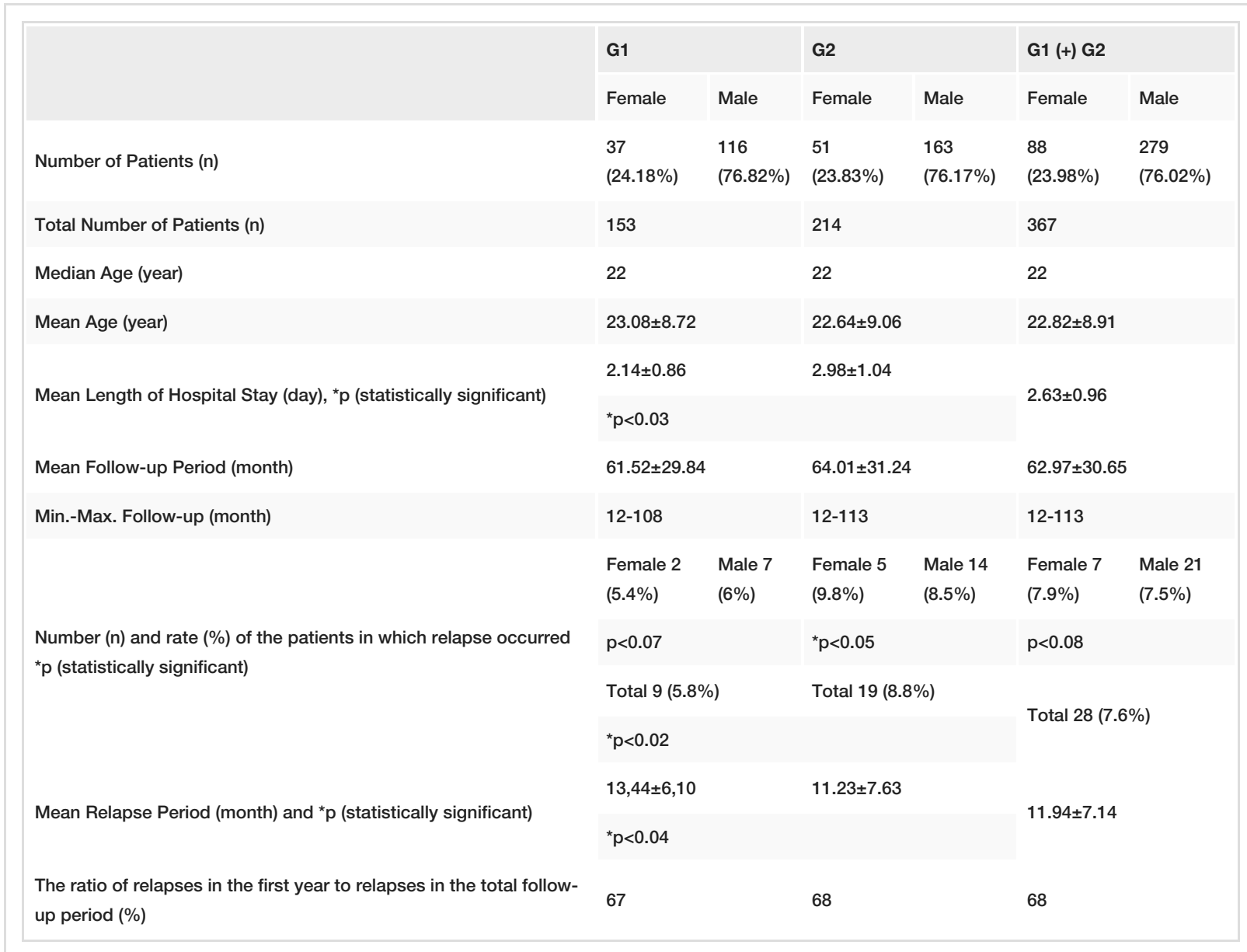

TABLE 1: Length of hospital stay and relapse rates after LFR according to the duration of SPSD symptoms

LFR: Limberg flap reconstruction; SPSD: sacrococcygeal pilonidal sinus disease

\section{Discussion}

In the study groups $(\mathrm{G} 1+\mathrm{G} 2)$, the patients' mean age was $22.82 \pm 8.91$ years, and the female-to-male ratio was approximately 1:3. Erkent et al. reported a mean age of 28.4 years and a female-to-male ratio of approximately 1:4 [8].

As we take a closer look at the results of LFRs performed in SPSD, the study conducted by Demiryas et al. pointed out that the mean relapse rate of patients treated with LFR for SPSD was 6\% at a mean follow-up period of $48.2 \pm 21.7$ months [9]. Another study performed by Boshnaq et al. indicated that the relapse rates of PSDs treated with LFR were 7.7\% at an 18-month follow-up period [10]. Milone et al. reported that the overall relapse rate was $13.8 \%$ in their meta-analysis covering a follow-up period of $58-240$ months, however, the relapse rates increased over $60 \%$ in some of their studies at 240 -month follow-up periods [11]. In another study remarkable for focusing on the relapse and follow-up periods, Stauffer et al. noted that relapse in PSD depends on both the surgical procedure and the follow-up period. Even though relapse rates seem to be lower in short-term follow-ups, higher rates are reported in long-term follow-ups [12]. In another study that we consider important since it represents a different point of view on the analysis of relapse, Burnett et al. have revealed that many surgeons have a positive perception of the success of therapies they administered since they do not keep abreast of relapses in those cases [13]. About $68 \%$ of the relapses in our study occurred in the first year and the difference between G1 and G2 was not significant ( $<0.8)$. Likewise, Halleran et al. reported that most relapses (80\%) in 307 cases included in their study occurred in the first year [14].

Another parameter in our study was to assess the length of hospital stay. On the basis of the available data, we concluded that the length of hospital stay was shorter in G1 patients ( $2.14 \pm 0.86$ days) in comparison to those in G2 (2.98 \pm 1.04 days), and the difference between the two groups was significant $\left({ }^{*} \mathrm{p}<0.03\right)$. This outcome suggests to us that a prolonged duration of symptoms, leading to those symptoms becoming complicated, results in a prolonged duration of therapy and increased costs. We have also found in the 
literature various results on the duration of hospital stay. Koca et al. noted that the length of postoperative hospital stay was $5.98 \pm 2.21$ days in patients with complicated pilonidal sinus treated with LFR and V-Y flap [15]. In another study, Sewefy et al. stated that the mean length of hospital stay after SPSD surgery was $4.9 \pm 2.4$ days [16]. Nonetheless, there are also relatively shorter lengths of hospital stay reported in the literature. Bayhan et al. reported that the length of hospital stay in the group treated with modified LFR for SPSD was $1.25 \pm 0.4$ days [17]. In their study, Zagory et al. indicated that they performed primary closure after pediatric SPSD resection and that the mean length of hospital stay was 0.67 days [18]. An increased length of hospital stay leads to an increase in both costs and labor loss.

The mean follow-up period of the 367 patients treated with LFR was $62.97 \pm 30.65$ months, and relapse occurred in 28 (7.6\%) patients. The relapse rate in all patients was $7.6 \%$, which was $5.8 \%$ in G1 patients and $8.8 \%$ in $\mathrm{G} 2$ patients ( ${ }^{*} \mathrm{p}<0.02$ ). The difference between G1 and G2 in terms of relapse rates suggests to us that a delay in surgery should be avoided in SPSD. At present, there are no similar studies examining the symptom onset period and the occurrence of relapse in the literature.

\section{Conclusions}

Taking into consideration the fact that one of the most important parameters proving success in SPSD therapy is to consider whether relapse has occurred or not and our suggestion to reduce recurrence, a delay in surgery should be avoided in SPSD. As can be seen from the study results, the sooner the surgery is performed, the lower the length of hospital stay and costs.

\section{Additional Information \\ Disclosures}

Human subjects: Consent was obtained by all participants in this study. Animal subjects: All authors have confirmed that this study did not involve animal subjects or tissue. Conflicts of interest: In compliance with the ICMJE uniform disclosure form, all authors declare the following: Payment/services info: All authors have declared that no financial support was received from any organization for the submitted work. Financial relationships: All authors have declared that they have no financial relationships at present or within the previous three years with any organizations that might have an interest in the submitted work. Other relationships: All authors have declared that there are no other relationships or activities that could appear to have influenced the submitted work.

\section{References}

1. Hodges RM: Pilonidal sinüs. Boston Med Surg J. 1880, 53:485-493.

2. Goliger JC: Pilonidal sinüs. Surgery of the Anus Rectum and Colon. Tindal B (ed): Elsevier, London; 1980. 1:200-215.

3. Hamoglu E, Yorgancı K: Plonidal sinüs. Basic Surgery. Sayek İ (ed): Güneș Bookstore, Ankara; 2013. 2:15481550.

4. Kartal A, Aydın HO, Oduncu M, Ferhatoğlu MF, Kıvılcım T, Filiz Aİ: Comparison of three surgical techniques in pilonidal sinus surgery. Prague Med Rep. 2018, 119:148-155. 10.14712/23362936.2019.2

5. Buie LA: Classic articles in colonic and rectal surgery 1890-1975: jeep disease (pilonidal disease of mechanized warfare) [Article in French]. Dis Colon Rectum. 1982, 25:384-390.

6. Harlak A, Mentes O, Kilic S, Coskun K, Duman K, Yilmaz F: Sacrococcygeal pilonidal disease: analysis of previously proposed risk factors. Clinics (Sao Paulo). 2010, 65:125-131. 10.1590/S1807-59322010000200002

7. Evers T, Doll D, Matevossian E, et al.: Trends in incidence and long-term recurrence rate of pilonidal sinus disease and analysis of associated influencing factors [Article in Chinese]. Zhonghua Wai Ke Za Zhi. 2011, 49:799-803.

8. Erkent M, Şahiner İT, Bala M, et al.: Comparison of primary midline closure, Limberg flap, and Karydakis flap techniques in pilonidal sinus surgery. Med Sci Monit. 2018, 11:8959-8963. 10.12659/MSM.913248

9. Demiryas S, Donmez T: Could early postoperative complications be considered as risk factor for recurrence after pilonidal sinus surgery?. Chirurgia. 2019, 114:475-486. 10.21614/chirurgia.114.4.475

10. Boshnaq M, Phan YC, Martini I, Harilingam M, Akhtar M, Tsavellas G: Limberg flap in management of pilonidal sinus disease: systematic review and a local experience. Acta Chir Belg. 2018, 118:78-84. 10.1080/00015458.2018.1430218

11. Milone M, Velotti N, Manigrasso M, Anoldo P, Milone F, De Palma GD: Long-term follow-up for pilonidal sinus surgery: a review of literature with metanalysis. Surgeon. 2018, 16:315-320. 10.1016/j.surge.2018.03.009

12. Stauffer VK, Luedi MM, Kauf P, et al.: Common surgical procedures in pilonidal sinus disease: a metaanalysis, merged data analysis, and comprehensive study on recurrence. Sci Rep. 2018, 15:3058. 10.1038/s41598-018-20143-4

13. Burnett D, Smith SR, Young CJ: The surgical management of pilonidal disease is uncertain because of high recurrence rates. Cureus. 2018, 14:2625. 10.7759/cureus.2625

14. Halleran DR, Lopez JJ, Lawrence AE, et al.: Recurrence of pilonidal disease: our best is not good enough . J Surg Res. 2018, 232:430-436. 10.1016/j.jss.2018.06.071

15. Koca YS, Yıldız I, Ugur M, Barut I: The V-Y flap technique in complicated and recurrent pilonidal sinus disease. Ann Ital Chir. 2018, 89:66-69.

16. Sewefy AM, Hassanen A, Atyia AM, Saleh SK: Karydakis flap with compressing tie-over interrupted sutures without drain versus standard Karydakis for treatment of sacrococcygeal pilonidal sinus disease. Dis Colon 


\section{Cureus}

Rectum. 2017 May, 60:514-520. 10.1097/DCR.0000000000000784

17. Bayhan Z, Zeren S, Duzgun SA, Ucar BI, Alparslan Yumun HN, Mestan M: Crystallized phenol application and modified Limberg flap procedure in treatment of pilonidal sinus disease: a comparative retrospective study. Asian J Surg. 2016, 39:172-177. 10.1016/j.asjsur.2015.12.007

18. Zagory JA, Golden J, Holoyda K, Demeter N, Nguyen NX: Excision and primary closure may be the better option in the surgical management of pilonidal disease in the pediatric population. Am Surg. 2016, 82:964967. 